\title{
Pengujian sensor fotodetektor sebagai alat ukur kadar gula pada larutan gula
}

\author{
Alex Taufiqurrohman Zain ${ }^{1 *}$, Cahyaning Nur Karimah ${ }^{1}$, Anni Nuraisyah ${ }^{2}$, Misto ${ }^{3}$ \\ $1^{*}$ Jurusan Teknik Politeknik Negeri Jember \\ 2Jurusan Produksi Pertanian Politeknik Negeri Jember \\ ${ }^{3}$ Fakultas Matematika Dan IImu Pengetahuan Alam Universitas Jember \\ ${ }^{\star}$ Corresponding Author email: Alextaufiqurrohman@polije.ac.id
}

\begin{tabular}{|c|c|}
\hline & Abstrak \\
\hline Diterima: & Fotodioda merupakan salah satu jenis fotodetektor. Fotodioda persambungan P-I-N (PIN) \\
\hline Bulan Januari & dipilih pada penelitian ini. Pemilihan ini didasarkan pada sensivitas yang tinggi dan \\
\hline 2020 & respon yang cepat terhadap setiap perubahan sinar. Fotodioda jenis BPW 34 digunakan \\
\hline & sebagai fotodetektor serta RGB bright LED sebagai sumber sinarnya. Pemilihan RGB \\
\hline & bright LED didasarkan pada kemampuannya untuk berganti spektrum sinar secara \\
\hline Diterbitkan: & otomatis didasarkan pada perubahan bit. Sebagai media perambatan sinar, diguanakan \\
\hline Bulan Februari & serat optik jenis single mode. Selain merancang perangkat keras, penelitian ini juga \\
\hline 2020 & merancang aplikasi melalui Arduino IDE 1.0.4 serta LabVIEW 2013 agar perangkat keras \\
\hline & mampu dikendalikan dan ditampilkan pada PC. Sebagai mikrokontroler, modul Arduino \\
\hline Keyword: & UNO digunakan pada penelitian ini. Hasil penelitian ini menunjukkan bahwa sinar pada \\
\hline Fotodioda, $R G B$ & RGB bright LED dapat dikendalikan melalui sistem bit pada PC (Personal Computer), \\
\hline $\begin{array}{l}\text { bright LED, } \\
\text { LabVIEW. }\end{array}$ & munculkan hasil pengukuran kandungan gula melalui PC. \\
\hline
\end{tabular}

\section{PENDAHULUAN}

Pendeteksian kadar glukosa dalam air destilasi menggunakan serat optik berbasis sensor pergeseran dengan probe bundel telah dikembangkan oleh Yasin et al., (2010). Penelitian tersebut menunjukkan bahwa intensitas sinar berbanding lurus dengan konsentrasi glukosa yang terkandung dalam air destilasi. Aini et al., (2013) juga melakukan pengujian kadar glukosa dalam air destilasi menggunakan serat optik berbasis sensor pergeseran dengan fiber coupler. Hasilnya penelitian tersebut menunjukkan bahwa semakin tinggi konsentrasi larutan glukosa yang digunakan, semakin tinggi tegangan keluaran yang dihasilkan.

Metode lain yang umum digunakan untuk mengukur kadar gula adalah dengan metode refractometric, Near Infrared Reflectance (NIR), polarimetric, dan kromatografi. Beberapa metode tersebut memiliki keterbatasan untuk digunakan di lapang karena membutuhkan waktu yang cukup lama, ketergantungan operator, dan membutuhkan reagen yang berbahaya. Beberapa penelitian di laboratorium telah menunjukkan bahwa metode spektroskopi dengan gelombang inframerah dapat berhasil digunakan untuk memprediksi kualitas tebu berdasarkan sampel nira tebu (Valderrama et al., 2007).

Penelitian ini dilaksanakan untuk mengetahui kandungan gula dari larutan dengan memanfaatkan fotodetektor yang selanjutnya terintegrasi dengan sistem pada personal computer (PC). Alat ukur yang dibuat memanfaatkan prinsip penjalaran sinar ketika sumber sinar melewati objek penelitian. Pada penelitian ini RGB (Red-GreenBlue) bright LED digunakan sebagai sumber sinar,
PIN fotodioda BPW 34 sebagai fotodetektor, dan serat optik sebagai media penjalaran. Modul Arduino UNO digunakan sebagai modul mikrokontroler untuk menghubungkan alat ukur yang dibuat dengan PC. Sedangkan objek penelitian yang digunakan adalah larutan gula.

Penelitian ini adalah langkah awal untuk mengembangkan alat ukur yang mampu terhubung dengan PC (personal computer). Tujuannya adalah setiap perubahan variabel, mampu dikendalikan dan dipantau. Selain itu history data yang terukur juga diharapkan mampu untuk disimpan sebagai pengembangan penelitian lebih lanjut.

\section{LANDASAN TEORI}

LED adalah salah satu komponen elektronika yang dapat mengeluarkan emisi cahaya. LED akan memancarkan cahaya saat diberikan arus listrik. LED hanya mampu mengeluarkan cahaya dengan panjang gelombang tertentu. Panjang gelombang tersebut akan ditangkap oleh mata manusia sebagai suatu sinar sehingga LED hanya memiliki satu warna saja (Sary, 2009). Secara simbolik LED dapat digambar dalam bentuk:

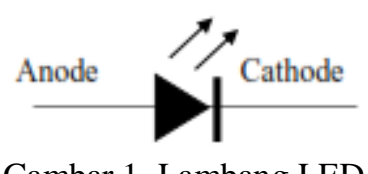

Gambar 1. Lambang LED

(Sumber: Sary, 2009)

LED termasuk dalam bahan semikonduktor sambungan p-n (PN) yang memancarkan sinar apabila diberi panjar maju. Elektron bebas pada bahan jenis dan akan berdifusi masuk ke dalam 
bahan jenis $\mathrm{p}$ dan sebaliknya hole pada bahan jenis $\mathrm{p}$ akan berdifusi masuk ke dalam bahan jenis $n$ melalui sambungan. Akibatnya, tepat pada sambungan p-n terjadi daerah tanpa muatan bebas yang biasa disebut sebagai daerah deplesi (Sutrisno, 1986). Setiap jenis LED mempunyai karakteristik tegangan dan arus yang berbeda. Semakin besar arus yang melewati LED maka semakin terang nyala dan daya yang dibutuhkan. Arus ini tidak boleh melebihi batas dari spesifikasi LED tersebut karena jika melebihi batas tersebut, maka LED akan rusak atau mungkin terbakar. Sehingga, untuk membatasi arus besar yang lewat maka diperlukan suatu resistor (Sary, 2009).

Menurut Wilson (2005) sensor pendeteksi cahaya dibagi dalam dua kategori utama yaitu detektor kuantum dan detektor suhu. Prinsip kerja dari detektor kuantum adalah seluruh radiasi dari sinar akan diubah menjadi elektron oleh perangkat semikonduktor, selanjutnya akan diproses dan menghasilkan arus pada rangkaian elektronika. Sedangkan detektor suhu memiliki prinsip kerja berupa penyerapan energi dari radiasi cahaya yang menyebabkan perubahan suhu sehingga detektor akan bekerja. Secara simbolik fotodioda dapat digambar dalam bentuk:

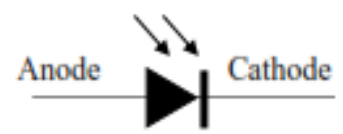

Gambar 2. Lambang fotodioda

(Sumber: Sary, 2009)

Fotodioda adalah suatu jenis dioda yang resistansinya berubah menyesuaikan dengan intensitas cahaya yang mengenainya. Semakin kuat cahaya yang jatuh pada dioda maka semakin kecil nilai tahanannya, sehingga arus yang mengalir semakin besar. Jika fotodioda persambungan $\mathrm{p}-\mathrm{n}$ yang diberi tegangan balik disinari, maka arus akan berubah secara linier dengan kenaikan fluks cahaya yang dikenakan pada persambungannya. Berdasarkan prinsip kerja tersebut dapat dibuat alat untuk mendeteksi intensitas cahaya dengan memanfaatkan karakteristik fotodioda yang selanjutnya dapat dikembangkan sebagai sensor yang peka terhadap intensitas cahaya yang mengenainya (Sary, 2009). Fotodioda termasuk dalam sensor optik yang terbuat dari bahan semikonduktor. Kegunaan dari sensor optik berbahan semikonduktor adalah mengubah sinyal masukan berupa optik menjadi sinyal keluaran berupa listrik (Abid, 2011). Sehingga fotodioda dapat digunakan sebagai detektor cahaya dengan mengamati arus yang mengalir melaluinya. Malvino (1984) menjelaskan bahwa fotodioda merupakan salah satu peralatan semikonduktor yang memiliki fungsi paling baik berdasarkan kepekaannya terhadap cahaya.
Pada fotodioda persambungan $\mathrm{p}-\mathrm{n}$, daerah deplesi pasangan muatan pembawa terpisah dan mengalir di dalam pengaruh medan listrik, sedangkan di luar daerah deplesi hole akan berdifusi ke daerah deplesi. Proses difusi berlangsung sangat lambat dibandingkan dengan aliran pasangan muatan sehingga berpengaruh terhadap pembatasan respon fotodioda. Namun pada fotodioda persambungan $\mathrm{p}-\mathrm{i}-\mathrm{n}$ (PIN), proses difusi dan aliran pembawa muatan berlangung begitu cepat dibandingkan pada fotodioda persambungan $\mathrm{p}-\mathrm{n}$ sehingga berpengaruh pada respon fotodioda yang begitu cepat. Karena respon yang begitu cepat terhadap sinar, fotodioda persambungan $\mathrm{p}-\mathrm{i}-\mathrm{n}$ dengan material semikonduktor InGaAs menjadi komponen penting dalam sistem komunikasi berbasis fiber optic.

Pertumbuhan industri jaringan telekomunikasi serat optik beberapa tahun terakhir membahas topik utama yang perlu dikembangkan yaitu kecepatan transmisi yang harus meningkat ketika saluran serat optik semakin kecil. Terdapat dua jenis serat optik yaitu Single mode fiber optic dan Multi mode fiber optic. Single mode fiber optic umumnya digunakan pada sistem telekomunikasi. Sedangkan Multi mode fiber optic biasanya digunakan pada sistem jaringan Local Area Network (Waluyo dan Agus, 2009).

Transmisi sinyal melalui serat optik memiliki keunggulan bila dibandingkan dengan sistem transmisi gelombang listrik maupun gelombang mikro, antara lain ukurannya sangat kecil dan ringan sehingga mudah dalam penanganan dan instalasinya, isyarat gelombang optik yang digunakan sebagai gelombang pembawa (carrier wave) tidak mudah terpengaruh oleh gangguan kelistrikan maupun medan magnetik. Selain itu, transmisi sinyal melalui serat optik memiliki lebar pita atau kapasitas transmisi yang besar sehingga dapat mengirimkan data dalam jumlah yang besar dan cepat (Widodo, 1995). Secara umum, sistem transmisi data analog menggunakan serat optik dinyatakan seperti pada gambar berikut:

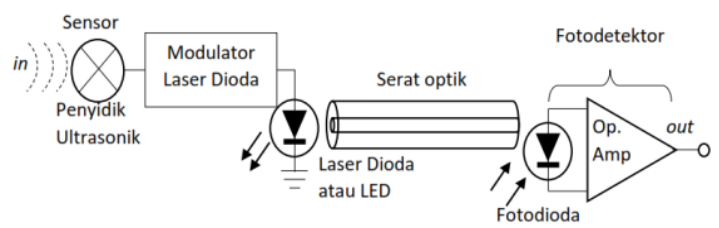

Gambar 3. Diagram blok sistem transmisi data mengggunakan serat optik

(Sumber: Waluyo dan Agus, 2009)

Karena yang digunakan adalah single mode fiber optic maka sumber cahaya yang digunakan adalah laser dioda atau LED (Waluyo dan Agus, 2009). Menurut Siswanto (2005) cahaya yang merambat dalam serat optik intensitasnya akan berkurang, pengurangan intensitas ini disebut atenuasi. Atenuasi disebabkan adanya penyerapan 
cahaya oleh bahan material serat optik serta penghamburan cahaya. Besarnya atenuasi tergantung jarak yang ditempuh dan karakteristik bahan serat optik. Sehingga untuk memperkuat keluaran diperlukan rangkaian penguat operasional. Berikut ini merupakan rangkaian penguat operasional yang digunakan:

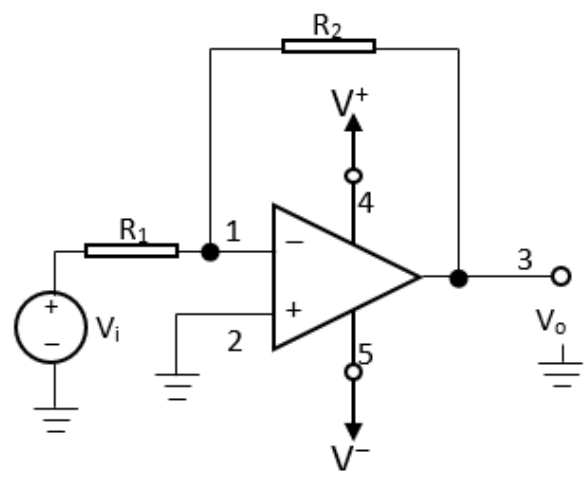

Gambar 4. Rangkaian penguat operasional

Penguat operasional atau Operational Amplifier (Op Amp) memiliki tiga terminal, yaitu dua terminal masukan dan satu terminal keluaran. Penguat operasional IC membutuhkan dua catu daya DC. Dengan kaki 1 dan 2 adalah terminal masukan, kaki 3 adalah terminal keluaran serta dua terminal lainnya yaitu terminal 4 dan 5 adalah terminal yang masing-masing dihubungkan dengan tegangan positif $\mathrm{V}^{+}$dan tegangan negatif $\mathrm{V}^{-}$dari catu daya.

\section{MATODE PENELITIAN}

Penelitian ini menggunakan mikrokontroler sebagai rangkaian mikrokontroler. Mikrokontroler adalah sistem komputer yang ringkas karena dapat menggantikan fungsi komputer dalam pengendalian kerja dengan desain yang jauh lebih ringkas dari pada komputer. Mikrokontroler hanya bisa digunakan untuk suatu aplikasi tertentu saja karena program kontrol disimpan pada ROM yang ukurannya relatif besar. Sedangkan RAM hanya digunakan untuk tempat penyimpanan sementara, termasuk register-register yang digunakan pada mikrokontroler yang bersangkutan (Pandiangan, 2007). Arduino adalah salah salah satu perangkat mikrokontroler. Arduino tersusun dari dua bagian utama yaitu Arduino board dan Arduino IDE (Integrated Development Environment). Arduino board berupa hardware atau modul yang digunakan ketika menyusun rangkaian. Sedangkan Arduino IDE merupakan software yang digunakan untuk pengolahan pada PC.

Pada penelitian ini, Arduino UNO digunakan sebagai modul mikrokontroler, sedangkan untuk input perintah, digunakan Arduino IDE 1.0.4. Pemilihan modul Arduino UNO dikarenakan hardware mikrokontroler Arduino UNO diprogram dengan menggunakan bahasa pemrograman wiring-based yang berbasiskan syntax dan library. Pemrograman wiring-based ini tidak berbeda dengan $\mathrm{C} / \mathrm{C}++$, tetapi dengan beberapa penyederhanaan dan modifikasi (Margolis, 2011). Berikut ini merupakan spesifikasi dari modul Arduino UNO:

Tabel 1. Karakteristik Arduino UNO

\begin{tabular}{lc}
\hline \multicolumn{1}{c}{ KOMPONEN } & SPESIFIKASI \\
\hline MIKROKONTROLER & ATMega328 \\
OPERATION VOLTAGE & $5 \mathrm{~V}$ \\
INPUT VOLTAGE & $7 \mathrm{~V}-12 \mathrm{~V}$ \\
& (rekomendasi) \\
INPUT VOLTAGE & $6 \mathrm{~V}-20 \mathrm{~V}$ (limit) \\
I/O & 14 pin $(6$ pin untuk \\
& PWM) \\
ELECTRIC CURRENT & $50 \mathrm{~mA}$ \\
\hline
\end{tabular}

LabVIEW merupakan software tambahan yang digunakan pada penelitian ini. LabVIEW menggunakan model aliran data (Dataflow programming) untuk menjalankan perintah. Secara garis besar terdapat dua bagian dalam penggunaan LabVIEW yaitu bagian node dan wire. Node dari block diagram akan dikerjakan ketika semua input tersedia. Ketika semua node sudah dikerjakan maka akan ada data yang ditampilkan pada output dan akan menuju ke node selanjutnya pada bagian aliran data (Halvorsen, 2014).

Dataflow programming memungkinkan melakukan pekerjaan dalam waktu yang bersamaan. Hal ini menyebabkan diagram mode multitasking dapat dengan mudah dijalankan. Multitasking merupakan kemampuan dasar yang dimiliki oleh LabVIEW yang secara tidak langsung dimiliki oleh bahasa pemrograman lainnya. Jika multiple nodes sudah siap dieksekusi, maka LabVIEW akan menggunakan proses yang disebut sebagai arbitrary unterleaving untuk menentukan node yang harus dikerjakan terlebih dahulu

Bahan yang digunakan pada penelitian ini merupakan larutan gula dengan 10 variasi konsentrasi yaitu $0 \mathrm{gr} / \mathrm{lt}, 25^{g r} / \mathrm{lt}, 50^{g r} / \mathrm{lt}, 75$ $g r / l t, 100 \mathrm{gr} /{ }_{l t}, 125^{g r} /{ }_{l t}, 150^{g r} /{ }_{l t}, 175^{g r} / l t$, $200^{g r} / l t$ dan $225^{g r} / l t$. Selanjutnya larutan gula tersebut dimasukkan ke dalam kuvet kaca yang sudah terisolir sinar dan berada di persambungan serat optik. Hal ini dilakukan agar mengetahui seberapa besar intensitas sinar yang mampu melewati sampel larutan gula.

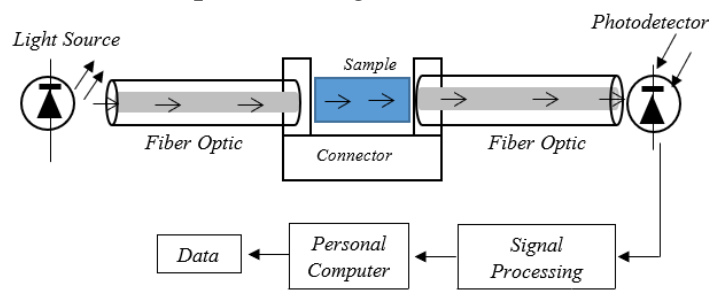

Gambar 5. Desain rangkaian alat ukur 
Penelitian ini memanfaatkan prinsip perambatan sinar. Sumber sinar LED menuju objek penelitian melalui serat optik. Selanjutnya, sinar LED akan melalui serat optik kembali dan intensitas sinar akan ditangkap oleh fotodioda PIN BPW 34 sebagai sinyal gelombang input. Output dari fotodioda PIN BPW 34 adalah kuat arus listrik. Karena besaran tersebut terbaca sangat kecil sehingga diperlukan rangkaian penguat operasional (Op Amp) agar ouput mampu terbaca oleh alat ukur serta mampu dikonversikan menjadi besaran tegangan.

Data tegangan yang terukur selanjutnya akan ditampilkan pada PC dengan bantuan pengolahan dari modul Arduino UNO serta penggabungan software Arduino IDE dan LabVIEW. Data awal yang didapatkan adalah kalibrasi alat yang dibuat terhadap alat standrat yang sudah ada. Pada penelitian ini, alat ukur standar yang digunakan sebagai pembanding adalah voltmeter digital. Selanjutnya dilakukan plotting data antara konsentrasi larutan gula yang diberikan (g/liter) terhadap data tegangan keluaran terukur dari alat yang dibuat $(\mathrm{mV})$.

\section{HASIL DAN PEMBAHASAN}

\section{Pengujian Rangkaian Pengendali RGB Bright LED}

Pada tahap pengujian sistem pengukur yang telah dibuat, terdapat dua pengujian alat yaitu pengujian hardware berupa rangkaian elektronika dan pengujian software berupa program yang digunakan untuk mengendalikan rangkaian elektronika menggunakan PC. Pengujian hardware dan software meliputi pengendalian sumber sinar RGB (red-green-blue) bright LED menggunakan PC dan hasil uji tegangan keluaran sistem terbaca di monitor PC. Agar sistem bisa dikendalikan dan hasilnya terbaca oleh PC maka diperlukan sebuah modul mikrokontroler berupa modul Arduino UNO. Untuk menjalankan mikrokontroler diperlukan perintah-perintah user melalui PC menggunakan bahasa pemrograman. Karena sistem alat ukur yang dibuat menggunakan modul Arduino UNO dan laptop maka software yang diperlukan terdiri dari software LabVIEW (yang mewakili perintah kerja dalam bentuk simbol-simbol) dan software Arduino IDE (yang mewakili perintah kerja dalam bentuk teks) maka diperlukan bahasa pemrograman untuk menggabungkan keduanya (menggunakan Firmata). Firmata merupakan protokol yang dituliskan pada Arduino IDE untuk memudahkan komunikasi serial Arduino IDE dengan software lainnya, termasuk LabVIEW. Firmata terdapat dalam program LIFA (LabVIEW Interface for Arduino). Program tersebut ditanamkan pada modul Arduino UNO melalui Arduino IDE. Adanya program LIFA yang tertanam pada modul Arduino UNO membuat modul Arduino UNO tidak lagi melakukan perintah kerja melalui hardware, melainkan hanya melalui software
LabVIEW (Artanto, 2012). Pada penelitian ini alat diatur untuk membaca nilai tegangan keluaran tiap 1 detik serta menghentikan pembacaan tegangan secara otomatis setelah 10 detik.

Block diagram merupakan salah satu dari jendela software LabVIEW yang digunakan sebagai tempat menuliskan perintah dan fungsi. Tampilan rangkaian program pengendalian RGB bright LED pada software LabVIEW adalah sebagai berikut:

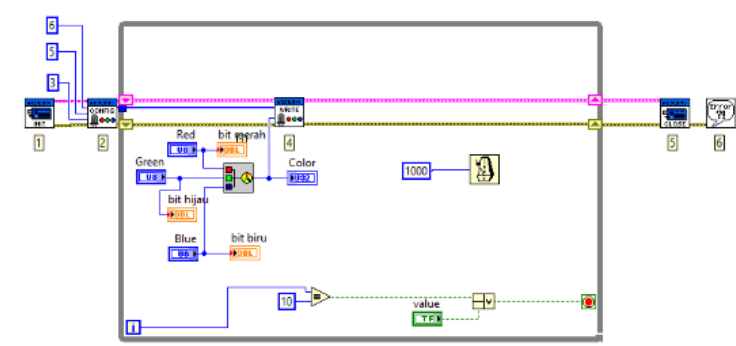

Gambar 6. Jendela block diagram LabVIEW untuk pengendalian RGB bright LED

Setiap kali pembuatan program, jendela block diagram diawali dengan simbol init.vi serta diakhiri dengan simbol close.vi. Simbol init.vi digunakan untuk mengatur komunikasi serial dari awal sebelum komunikasi dilangsungkan, termasuk port yang digunakan, kecepatan komunikasi, modul Arduino yang digunakan dan lain-lain. Sedangkan simbol close.vi digunakan untuk menutup komunikasi dengan modul Arduino UNO. Untuk pengendalian RGB bright LED digunakan simbolsimbol RGB LED configure.vi, RGB LED write.vi, dan $R G B$ to Color.vi.

Jendela lain yang muncul ketika menjalankan software LabVIEW adalah jendela front panel. Jendela ini digunakan untuk menjalankan program yang sudah dibuat serta menampilkan hasil eksekusi dari perintah-perintah yang sudah dibuat pada jendela block diagram. Adapun tampilan dari jendela front panel untuk pengendalian RGB bright LED adalah:

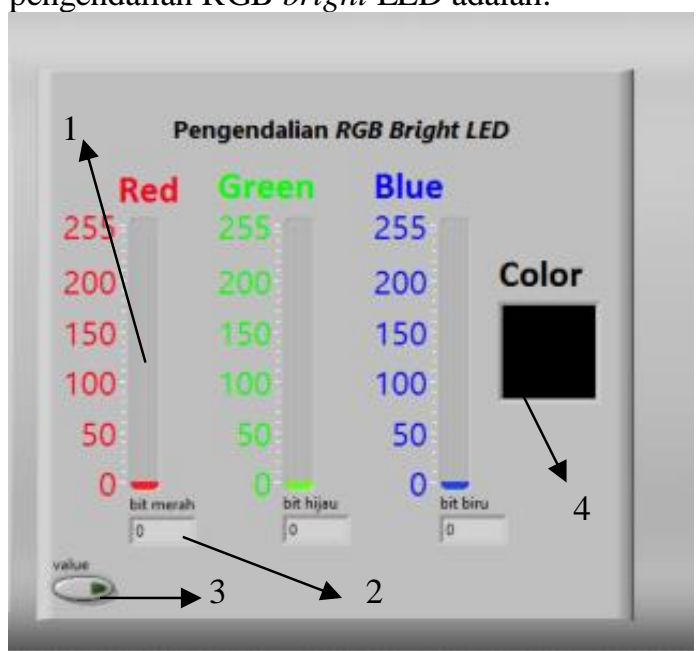

Gambar 7. Jendela front panel LabVIEW untuk pengendalian RGB bright LED 
Selain dapat diatur dengan menggeser skala bit (Bagian 1), input bit yang diinginkanjuga dapat diatur dengan memasukkan langsung nilai bit pada masing-masing kolom yang sudah tersedia (Bagian 2). Ketika pengendalian pada RGB bright LED berhasil maka indikator value (Bagian 3) akan menyala. Sedangkan indikator color (Bagian 4) akan menampilkan warna yang yang dihasilkan, sesui dengan bit yang diberikan. RGB bright LED memiliki tiga warna dasar yaitu merah, hijau dan biru. Terdapat empat kaki dari RGB bright LED masing-masing berupa anoda sumber sinar merah, anoda sumber sinar hijau, anoda sumber sinar biru dan satu buah ground. Masing-masing anoda tersebut dihubungkan dengan modul Arduino UNO pada soket digital PWM. Sedangkan kaki ground dari RGB bright LED dihubungkan dengan port GND pada modul Arduino UNO. Ketiga warna dari RGB bright LED dapat dikendalikan dengan PC memanfaatkan sistem bit. Selain itu dengan sistem ini, dapat pula dihasilkan warna-warna sekunder lainnya. Pada penelitian ini warna sinar RGB bright LED yang digunakan adalah warna kuning dan ungu, dengan spesifikasi bit sebagai berikut:

Tabel 2. Hasil pengujian pada kendali RGB bright LED menggunakan software LabVIEW

\begin{tabular}{ccccc}
\hline \multirow{2}{*}{ No } & \multicolumn{2}{c}{ Bit } & \multicolumn{2}{c}{ Keadaan RGB bright } \\
\cline { 2 - 4 } & Merah & Hijau & Biru & LED \\
\hline $\mathbf{1}$ & 0 & 0 & 0 & LED mati \\
$\mathbf{2}$ & 255 & 0 & 255 & kuning-terang \\
$\mathbf{3}$ & 150 & 150 & 0 & ungu-terang \\
$\mathbf{4}$ & 255 & 255 & 255 & putih-terang \\
\hline
\end{tabular}

\section{Pembacaan Tegangan Keluaran}

Sensor fotodioda PIN yang digunakan adalah sensor fotodioda PIN BPW 34. Fotodioda ini memiliki luasan tangkapan foton sebesar 7,5 mm serta respon puncak di daerah panjang gelombang $900 \mathrm{~nm}$. Fotodioda BPW 34 akan menerima sinar dari setat optik dan mengubahnya menjadi besaran listrik. Karena adanya efek atenuasi maka keluaran dari fotodioda BPW 34 dihubungkan dengan rangkaian penguat operasional (Op Amp) seperti pada Gambar 4. Selanjutnya tegangan yang dhasilkan oleh rangkaian Op Amp dapat terbaca pada PC. Adapun block diagram pada LabVIEW untuk pembacaan tegangan adalah sebagai berikut:

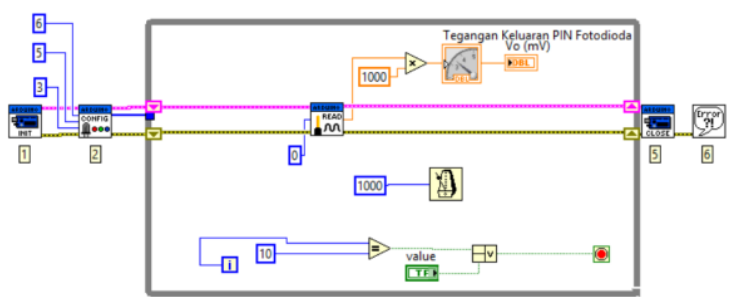

Gambar 8. Jendela block diagram LabVIEW untuk pembacaan tegangan keluaran

Pada pembacaan tegangan keluaran rangkaian Op Amp digunakan simbol Analog Read Pin.vi. Adapun fungsi dari simbol tersebut adalah untuk membaca nilai tegangan analog. Jendela front panel yang muncul pada PC untuk menampilkan hasil pengukuran tegangan keluaran adalah sebagai berikut:

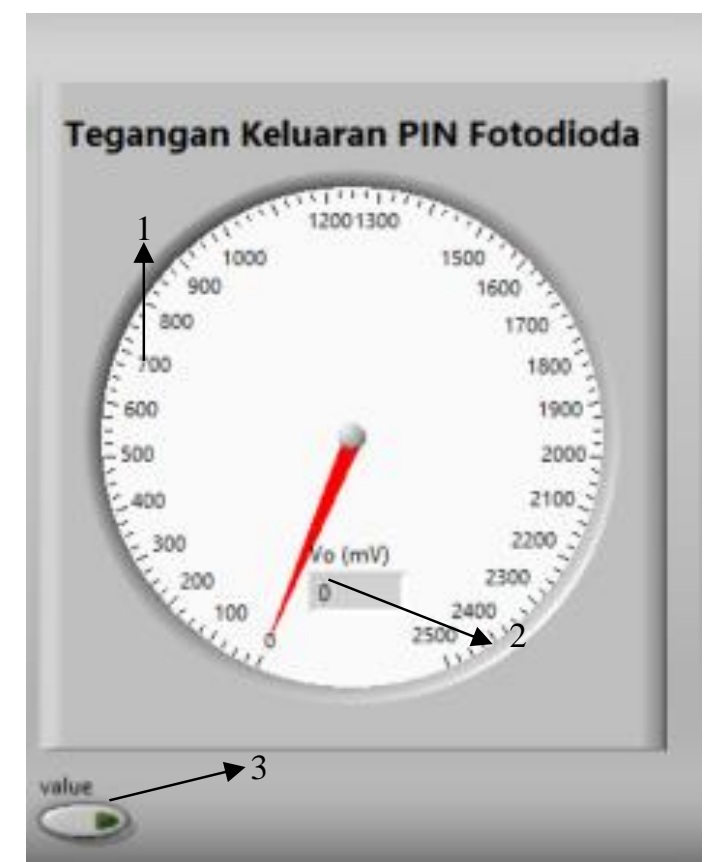

Gambar 7. Jendela front panel LabVIEW untuk pembacaan tegangan keluaran

Selain ditampilkan dalam bentuk skala (Bagian 1), tegangan keluaran yang terukur akan ditampilkan pada kolom Vo (Bagian 2) dalam orde $\mathrm{mV}$. Seperti halnya pada pembahasan sebelumnya, terdapat indikator value (Bagian 3) yang akan menyala jika sistem pembacaan sudah berhasil.

\section{Pengukuran Kandungan Gula}

Tahap selanjutnya adalah pengujian alat secara keseluruhan untuk mengukur kandungan gula pada larutan. Sebagai alat ukur pembanding, maka digunakan voltmeter digital untuk mengukur tegangan keluaran. Adapun sinar RGB bright LED yang digunakan untuk penelitian ini adalah warna kuning-terang dan ungu-terang dengan spesifikasi pengaturan bit seperti pada tabel 2. Berdasarkan hal tersebut maka diketahui bahwa sinar yang diguanakan adalah sinar tampak. Sinar tampak memiliki frekuensi dan panjang gelombang sebagai berikut:

Tabel 3. Nilai aproksimasi dari frekuensi dan panjang gelombang sinar tampak

\begin{tabular}{ccc}
\hline Warna & $\lambda_{0}(\mathbf{n m})^{*}$ & $\boldsymbol{f}(\mathbf{T H z})^{* *}$ \\
\hline Merah & $780-622$ & $384-482$ \\
Jingga & $622-597$ & $482-503$ \\
Kuning & $597-577$ & $503-520$ \\
Hijau & $577-492$ & $520-610$ \\
Biru & $492-455$ & $610-659$ \\
Ungu & $455-300$ & $659-769$ \\
\hline
\end{tabular}


$* 1$ nanometer $(\mathrm{nm})=10^{-9} \mathrm{~m}$,

$* * 1$ teraHertz $(\mathrm{THz})=10^{12} \mathrm{~Hz}$

(Sumber: Hecht, 2002)

Berikut merupakan hasil pengukuran kandungan gula pada larutan:

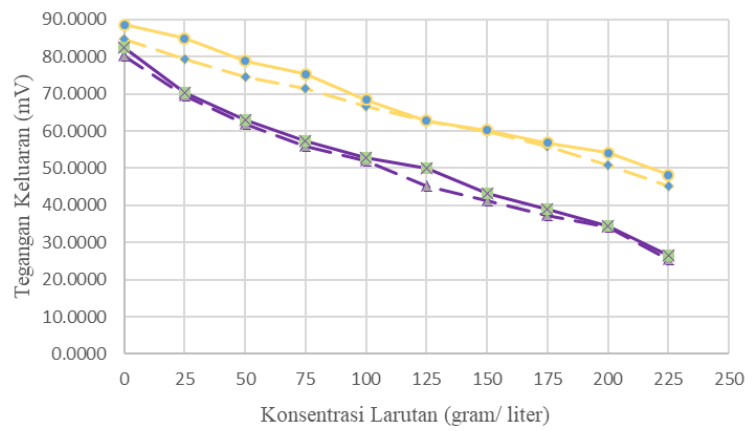

Gambar 9. Hasil pengukuran kandungan gula pada larutan

Gambar 9 menunjukkan hasil pengukuran menggunakan alat yang dirancang (disebut sebagai fotodetektor) dibandingkan dengan alat ukur konvensional dalam hal ini voltmeter digital. Grafik berwarna kuning mengindikasikan penggunaan sinar warna kuning dan sebaliknya, grafik warna ungu adalah penggunaan sinar warna ungu. Selanjutnya, garis putus adalah pengukuran menggunakan fotodetektor dan garis lurus adalah pengukuran menggunakan voltmeter digital. Berdasarkan hasil tersebut, keempat grafik menunjukkan pola yang sama, yaitu adanya penurunan tegangan keluaran setiap penambahan konsentrasi larutan gula. Hal ini disebabkan oleh adanya zat terlarut yang bertambah yang akan memperbanyak penyerapan sinar. Sehingga sinar yang mampu tertangkap oleh fotodetektor akan semakin berkurang.

Jika ditinjau dari variasi alat ukur, baik sinar kuning maupun ungu menghasilkan nilai tegangan yang lebih rendah jika diukur menggunakan fotodetektor dibandingkan dengan pengukuran menggunakan voltmeter digital. Hal ini disebabkan oleh adanya keterbatasan pada spesifikasi alat yang dibuat terutama pada modul mikrokontroler sebagai modul utama pengiriman dan penerimaan sinyal. Sedangkan jika dilihat dari variasi warnanya, baik pengukuran menggunakan fotodetektor maupun pengukuran menggunakan voltmeter digital, dapat diketahui bahwa sinar kuning mampu menghasilkan tegangan keluaran yang lebih besar dibandingkan dengan sinar ungu.

\section{PENUTUP}

Kesimpulan
Berdasarkan penelitian yang telah dilakukan, diperoleh kesimpulan bahwa alat ukur yang dibuat sudah dapat bekerja dengan baik. Hal tersebut dapat dilihat dari pola data yang sama. Meski demikian penelitian lebih lanjut diperlukan untuk mendapatkan hasil yang lebih akurat sesuai dengan alat ukur standart (voltmeter digital). Sinar kuning menghasilkan nilai tegangan keluaran yang lebih besar dibandingkan dengan sinar ungu. Hal ini disebabkan oleh karakteristik larutan gula yang lebih mudah menyerap sinar ungu dibandingkan dengan sinar kuning.

\section{REFERENSI}

Abid, Kamran. 2011. Gated Lateral Silicon p-i-n Junction Photodiodes. Glasgow: University of Glasgow.

Aini, Fina Nurul, Samian, dan Moh. Yasin. 2013. Deteksi Kadar Glukosa dalam Air Destilasi Berbasis Sensor Pergeseran Menggunakan Fiber Coupler. Jurnal Fisika dan Terapannya, ISBN 9772337 300009. 1 (1): 1-7.

Artanto, Dian. 2012. Interaksi Arduino dan LabVIEW. Jakarta: PT Elex Media Komputindo.

Halvorsen, Hans-Petter. 2014. Introduction to LabVIEW. Norwegia: Telemark University College.

Malvino, Albert Paul. 1984. Electronic Principles. 3rd Edition. McGraw-Hill, Inc.

Margolis, Michael. 2011. Arduino Cookbook. US A: O'Reilly Media, Inc.

Pandiangan, Johannes. 2007. Perancangan dan Penggunaan Photodioda sebagai Sensor Penghindar Dinding Pada Robot Forklift. Medan: Universitas Sumatera Utara.

Sary, Yusnita Tanjung. 2009. Rancang Bangun Sistem Pendeteksi Jenis nira Menggunakan Deret Led Dan Metode Jaringan Syaraf Tiruan. Surabaya: Institut Teknologi Sepuluh Nopember.

Siswanto, Oktavianto Utomo. 2005. Analisis Perhitungan Rugi-Rugi pada Serat Optik. Semarang: Universitas Diponegoro.

Sutrisno. 1986. Elektronika Jilid 1: Teori dan Penerapannya. Bandung: ITB.

Valderrama, P., Braga, J. W. B., \& Poppi, R. J. 2007. Validation of Multivariate Calibration Models in the Determination of Sugarcane Quality Parameters by Near Infrared Spectroscopy. J. Braz. Chem. Soc., 18: 259266.

Waluyo, Tomi Budi dan Agus Suheri. 2009. Penggunaan Serat Optik Ragam Tunggal untuk Transmisi Data Pengukuran, Jurnal Fisika Himpunan Fisika Indonesia, ISSN: 0854-3046. 9 (1): 20-28.

Widodo, S. T. 1995. Optoelektronika. Yogyakarta: Andi. 
http://jurnal.uts.ac.id Science and Technology

Wilson, Jon. 2005. Sensor Technology Handbook. Oxford: Elseiver Inc.

Yasin M., Harun S. W., Yang H. Z. \& Ahmad H. 2010. Fiber Optic Displacement Sensor for
Measurement of Glucose Concentration in Distilled Water. Optoelectronics and Advanced Materials - Rapid Communications, 4 (8): 1063-1065 